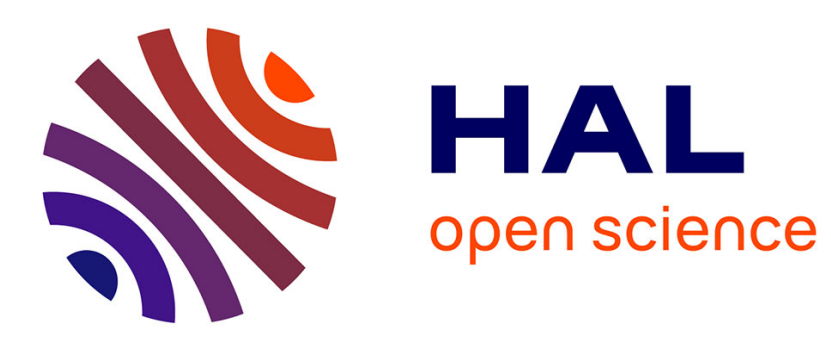

\title{
Thermodynamic Simulation of YBa2Cu3O6+x Film Growth Using Aerosol MOCVD
}

\author{
F. Weiss, A. Pisch, C. Bernard, U. Schmatz
}

\section{To cite this version:}

F. Weiss, A. Pisch, C. Bernard, U. Schmatz. Thermodynamic Simulation of YBa2Cu3O6+x Film Growth Using Aerosol MOCVD. Journal de Physique IV Proceedings, 1995, 05 (C5), pp.C5-151-C5158. 10.1051/jphyscol:1995516 . jpa-00253841

\section{HAL Id: jpa-00253841 https://hal.science/jpa-00253841}

Submitted on 1 Jan 1995

HAL is a multi-disciplinary open access archive for the deposit and dissemination of scientific research documents, whether they are published or not. The documents may come from teaching and research institutions in France or abroad, or from public or private research centers.
L'archive ouverte pluridisciplinaire HAL, est destinée au dépôt et à la diffusion de documents scientifiques de niveau recherche, publiés ou non, émanant des établissements d'enseignement et de recherche français ou étrangers, des laboratoires publics ou privés. 


\title{
Thermodynamic Simulation of $\mathrm{YBa}_{2} \mathrm{Cu}_{3} \mathrm{O}_{6+x}$ Film Growth Using Aerosol MOCVD
}

\author{
F. Weiss*, A. Pisch*,**, C. Bernard** and U. Schmatz* \\ *INPG-ENSPG-LMGP, B.P. 46, 38402 Saint-Martin d'Hères, France \\ ** INPG-ENSEEG-LTPCM, B.P. 75, 38402 Saint-Martin d'Hères, France
}

\begin{abstract}
Future high power applications of high $\mathrm{T}_{\mathrm{c}}$ superconducting materials (like $\mathrm{YBa}_{2} \mathrm{Cu}_{3} \mathrm{O}_{6+x}$ ) demand thick films with excellent electrical properties. The use of thin film deposition techniques is only possible when high deposition rates can be reached.

A novel aerosol MOCVD technique using a liquid source has recently been developed and is very promising for this purpose. The precursor materials used are the $\beta$-diketonates of yttrium, barium and copper, dissolved in diethylene glycol dimethyl ether ("diglyme") in various concentrations.

A preliminary thermodynamic simulation of the process is a useful tool for a deeper understanding of the stability limits of the superconducting phase and the on-going reactions during deposition. The results of these simulations have been used to optimise the process conditions for $\mathrm{YBa}_{2} \mathrm{Cu}_{3} \mathrm{O}_{6+x}$ growth with good superconducting properties.

A comparison between the simulation and the experimental results will be given and the influence of the main process parameters (deposition temperature, oxygen partial pressure, precursor concentration, ...) will be shown.
\end{abstract}

\section{INTRODUCTION}

Since the discovery of high temperature superconducting ceramics, it has been anticipated, that these materials would have a wide range of applications in microelectronics (microwave, antennas, squids, bolometers,...) and in high current devices (wires, tapes,...). These devices for high current applications can either be realised via bulk techniques (melt texturing, melt and quench,...) or thick film processes. Among all different deposition techniques, chemical vapour deposition can be attractive, if high growth rates can be attained. The advantages of this process type are manifold: good growth control, deposition on non-planar objects is possible, the experimental set-up is rather inexpensive and compatible with an industrial environment.

One of the most studied materials among these high $\mathrm{T}_{\mathrm{c}}$ oxides is $\mathrm{YBa}_{2} \mathrm{Cu}_{3} \mathrm{O}_{6+\mathrm{x}}$, because it has been the first compound with a superconducting transition temperature $\left(\mathrm{T}_{\mathrm{C}}=92 \mathrm{~K}\right.$ ) higher than the boiling point of nitrogen and it does not contain any toxic elements. The lack of suitable inorganic precursor materials (like for example halides) has led to the use of metalorganic compounds for film deposition by CVD. Most of these metalorganic precursors belong to the $\beta$-diketonate family, with an extensive use of $Y(t m h d)_{3}$, $\mathrm{Ba}(\mathrm{tmhd})_{2}$ and $\mathrm{Cu}(\mathrm{tmhd})_{2}$ (tmhd = tetramethylheptanedionate, $\mathrm{C}_{11} \mathrm{H}_{19} \mathrm{O}_{2}$ ). The precursors for yttrium and copper have reasonable volatility and stability at moderate temperatures (around $100^{\circ} \mathrm{C}$ ). Only $\mathrm{Ba}(\mathrm{tmhd})_{2}$, like all other alkaline earth element precursors has to be heated to temperatures higher than $200^{\circ} \mathrm{C}$, which affects its long term vaporisation stability. Oligomerisation can occur which decreases volatility, leading to a compositional shift in the gas phase and in the film during $\mathrm{YBa}_{2} \mathrm{Cu}_{3} \mathrm{O}_{6+x}$ deposition. Consequently, reproducibility and maximum growth rate for the classical MOCVD process are limited. 
Schmaderer et al. [1] have shown, that the maximum growth rate for deposition temperatures higher than $600^{\circ} \mathrm{C}$ is only limited by mass transport towards the substrate. Alternative MOCVD techniques, which bypass the encountered problems has though been developed. The basic principles of these methods are either flash evaporation of a powder mixture [2] or evaporation of a sprayed solution, where the metalorganic precursors are dissolved in a suitable solvent $[3,4,5]$. The latter approach offers an improved composition control of the deposited films as well as high growth rates. The main advantage of the aerosol MOCVD technique, against conventional MOCVD, is that metal-organic precursors are exposed to elevated temperatures only during the short time necessary for their evaporation. The composition control and the reproducibility of the process are therefore substantially improved. Furthermore, the aerosol MOCVD process, due to the possibility to transport a large amount of precursors to the preheating zone, yields higher partial pressures of the reacting species in the gas phase and, consequently, gives rise to an improved growth rate.

Very quickly after the discovery of $\mathrm{YBa}_{2} \mathrm{Cu}_{3} \mathrm{O}_{6+x}$, it has become clear, that the quality of the samples in terms of phase purity and grain structure plays a crucial role on the electrical properties. For example some secondary phases $\left(\mathrm{BaCO}_{3}\right)$ and high angle grain boundaries lower the critical temperature and can drop the critical current density for orders of magnitude. Other secondary phases like CuO and $\mathrm{Y}_{2} \mathrm{BaCuO}_{5}$, when present as small inclusions, epitaxially inside a $\mathrm{YBa}_{2} \mathrm{Cu}_{3} \mathrm{O}_{6+x}$ matrix, can increase $\mathrm{jc}_{\mathrm{c}}$ considerably due to vortex pinning phenomena. So, the control of the nature and the amount of these secondary phases is vital to optimise a specific synthesis process. Thermodynamic equilibrium calculations are an attractive and powerful tool to reach this goal, if the complete phase diagram is known and reliable Gibbs energy data for all compounds in the chemical systems have been assessed. For the classical MOCVD process with different precursor materials, studies have already been carried out [6,7]. We apply this same approach to the aerosol MOCVD technique, using newly assessed, more reliable thermodynamic data to determine the influence and the sensibility of the main experimental parameters and to optimise the process conditions.

\section{EXPERIMENTAL}

A detailed description of the preparation of the $\mathrm{YBa}_{2} \mathrm{Cu}_{3} \mathrm{O}_{6+x}$ films by aerosol MOCVD is published elsewhere [3] and the important features are just summed up. The three metalorganic tmhd complexes of $Y$, $\mathrm{Ba}$ and $\mathrm{Cu}$ are dissolved in diethylene glycol dimethyl ether ("diglyme", $\mathrm{C}_{6} \mathrm{H}_{14} \mathrm{O}_{3}$ ) in various $\mathrm{Y}: \mathrm{Ba}: \mathrm{Cu}$ ratios and an overall precursor concentration of 0.02 mole $/ 1$. This solution is transformed into a mist of microscopic droplets by a piezoelectric transducer $(800 \mathrm{kHz}, 50 \mathrm{~W})$. This mist forms at the liquid-gas interface and is immediately transported by Ar as carrier gas towards the preheating zone for evaporation. The temperature and the length of this zone has to be adjusted to assure a complete evaporation of the solution droplets (solvent+precursors). In our case, the minimum temperature is defined by $\mathrm{Ba}(\mathrm{tmhd})_{2}$ and is set to $250^{\circ} \mathrm{C}$. The oxygen gas, necessary to form the superconducting phase, is introduced separately and mixed with the other vapours at the upper end of the evaporation zone. The substrate (single crystalline $\mathrm{MgO}<100>$ or $\mathrm{SrTiO}_{3}<100>$ ) is fixed on a stainless steel susceptor, which is heated induclively. The deposition temperature is measured with a thermocouple in the susceptor. The total gas pressure during deposition has to be higher than the vapour pressure in order to avoid a boiling of the solution. For pure diglyme one can find a literature value of 7,5 Torr at room temperature and therefore a total deposition pressure of 10 Torr has been chosen. Typical deposition time is 5 to $20 \mathrm{~min}$ and the resulting growth rate is estimated to be $3-4 \mu \mathrm{m} / \mathrm{h}$. The overall carrier gas flow $\left(\mathrm{Ar}+\mathrm{O}_{2}\right)$ has been determined to guarantee homogeneous film thickness and composition over the entire substrate. After deposition, the films are cooled down to room temperature in 760 Torr of pure oxygen to transform the insulating $\mathrm{YBa}_{2} \mathrm{Cu}_{3} \mathrm{O}_{6}$ phase into the superconducting compound.

Different experimental techniques have been used to characterise the samples. For structural investigations and to identify secondary phases, X-ray diffraction in the Bragg-Brentano geometry, using $\mathrm{CuK} \alpha$ radiation, has been employed. The chemical composition and the morphology of the layer's have been determined by scanning electron microscopy coupled to an EDX system (calibrated by RBS measurements). The superconducting properties have been determined by a standard four probe a.c. resistivity technique $(8 \mathrm{~Hz}, 0.1 \mathrm{~mA})$ and by the measurement of the a.c. screening capability $(800 \mathrm{~Hz}, 20$ $\mathrm{mOe}$. The critical current density as a function of temperature has been deduced from the a.c. screening measurements. by scaling with direct transport measurements the position of the imaginary part peak as function of temperature for different applied a.c. fields ( $20 \mathrm{mOe}-20 \mathrm{Oe}$ ). 


\section{THERMODYNAMIC PROCESS SIMULATION}

\subsection{Choice of experimental parameters}

The basic principle of thermodynamic equilibrium calculations is the minimisation of the total Gibbs free energy of the chemical system involved in the process. The first and most important step is the compilation of a complete and reliable set of thermodynamic data for all species (condensed or gaseous) likely to be present at equilibrium. In the case of the $\mathrm{Y}$-Ba-Cu-O-C-H-Ar this assessment work has been done in the frame of the Brite/Euram SUPERDATA project $[8,9]$. The computer program used for the calculations is "Mélange", developed by J. N. Barbier and C. Bernard [10].

The aerosol MOCVD process simulation includes 22 condensed phases $\left(\mathrm{Y}, \mathrm{Y}_{2} \mathrm{O}_{3}, \mathrm{Ba}, \mathrm{BaO}, \mathrm{BaO}_{2}\right.$, $\mathrm{BaCO}_{3}, \mathrm{Cu}, \mathrm{CuO}, \mathrm{Cu}_{2} \mathrm{O}, \mathrm{CuCO}_{3}, \mathrm{C}, \mathrm{YCuO}_{2}, \mathrm{Y}_{2} \mathrm{Cu}_{2} \mathrm{O}_{5}, \mathrm{Ba}_{2} \mathrm{CuO}_{3}, \mathrm{BaCuO}_{2}, \mathrm{BaCu}_{2} \mathrm{O}_{2}, \mathrm{Y}_{2} \mathrm{BaO}_{4}$, $\mathrm{Y}_{3} \mathrm{Ba}_{4} \mathrm{O}_{9}, \mathrm{Y}_{2} \mathrm{BaCuO}_{5}, \mathrm{YBa}_{4} \mathrm{Cu}_{3} \mathrm{O}_{8.5}, \mathrm{YBa}_{6} \mathrm{Cu}_{3} \mathrm{O}_{10.5}$ and $\mathrm{YBa}_{2} \mathrm{Cu}_{3} \mathrm{O}_{6+\mathrm{x}}$ ) and a complex gas phase with 30 different species ( $\mathrm{Ar}, \mathrm{O}, \mathrm{O}_{2}, \mathrm{O}_{3}, \mathrm{H}, \mathrm{H}_{2}, \mathrm{HO}, \mathrm{HO}_{2}, \mathrm{H}_{2} \mathrm{O}, \mathrm{H}_{2} \mathrm{O}_{2}, \mathrm{CO}, \mathrm{CO}_{2}, \mathrm{C}_{2} \mathrm{O}, \mathrm{C}_{3} \mathrm{O}_{2}, \mathrm{CHO}, \mathrm{CH}_{2} \mathrm{O}$, $\left.\mathrm{CH}_{4} \mathrm{O}, \mathrm{C}_{2} \mathrm{H}_{4} \mathrm{O}, \mathrm{Y}, \mathrm{YO}, \mathrm{Y}_{2} \mathrm{O}, \mathrm{YO}_{2}, \mathrm{Y}_{2} \mathrm{O}_{2}, \mathrm{Ba}, \mathrm{BaO}, \mathrm{Ba} 2 \mathrm{O}, \mathrm{BaOH}, \mathrm{Ba}(\mathrm{OH})_{2}, \mathrm{Cu}, \mathrm{CuO}\right)$. The nonstoichiometry of the superconducting phase has been described with a four sublattice model, which has been adjusted to experimental $\mathrm{pO}_{2}-\mathrm{x}$ data. No thermodynamic data is available for the metalorganic precursors and therefore positive Gibbs energy values have been attributed to these compounds in order to assure their complete decomposition at the substrate surface. The different input parameters for the calculations with their typical values are summed up in table 1.

\begin{tabular}{ll}
$\begin{array}{l}\text { total gas pressure } \\
\text { total carrier gas flow }\end{array}$ & $10 \mathrm{Torr}$ (fixed) \\
& $27 \mathrm{l} / \mathrm{h}$ (fixed) \\
precursor concentration & $0.02-0.1 \mathrm{~mole} / \mathrm{l}$ \\
$\begin{array}{l}\text { solution feeding speed } \\
\text { deposition temperature }\end{array}$ & $6-20 \mathrm{ml} / \mathrm{h}$ \\
\hline
\end{tabular}

Table 1: Typical calculation input values for the experimental parameters

\subsection{Simulation results}

The gas phase is after reaction basically constituted of four different compounds: $\mathrm{Ar}, \mathrm{O}_{2}, \mathrm{CO}_{2}$ and $\mathrm{H}_{2} \mathrm{O}$. All other gas species, and especially those which contain metal atoms, have negligible partial pressures, i.e. all metal atoms in the solution before reaction will be deposited as condensed phases from a thermodynamic point of view (this is actually not true, because of very different diffusion coefficients of the three tetramethylheptandionates).

\subsubsection{Influence of the solution feeding speed}

The condensed phases present in the film after reaction have been computed as a function of deposition temperature and solution feeding speed. The overall precursor concentration has been fixed to 0.02 mole/l (with $\left.\mathrm{Y}(\mathrm{tmhd})_{3}: \mathrm{Ba}(\mathrm{tmhd})_{2}: \mathrm{Cu}(\mathrm{tmhd})_{2}=1: 2: 3\right)$. The stability of the superconducting phase for different oxygen to argon input ratios $(14.9,5.7,3.3)$ is plotted in figure 2 . Two different decomposition reactions can be distinguished. For temperatures lower than $\sim 800^{\circ} \mathrm{C}, \mathrm{YBa}_{2} \mathrm{Cu}_{3} \mathrm{O}_{6+x}$ decomposes into $\mathrm{Y}_{2} \mathrm{BaCuO}_{5}$, $\mathrm{BaCO}_{3}$ and $\mathrm{CuO}$. The corresponding solution feeding speed shows an exponential behaviour as a function of temperature. This stability limit is almost independant of the initial $\mathrm{O}_{2} / \mathrm{Ar}$ values. For higher temperatures, $\mathrm{CuO}$ transforms into $\mathrm{Cu}_{2} \mathrm{O}$ and the slope of the stability limit changes to an almost linear behaviour. The actual value for the maximum solution feeding speed to deposit the superconducting compound depends now considerably on the oxygen partial pressure. The higher the oxygen partial pressure value is, the higher solution feeding speeds can be attained (i.e. increased mass transport = growth rate). 


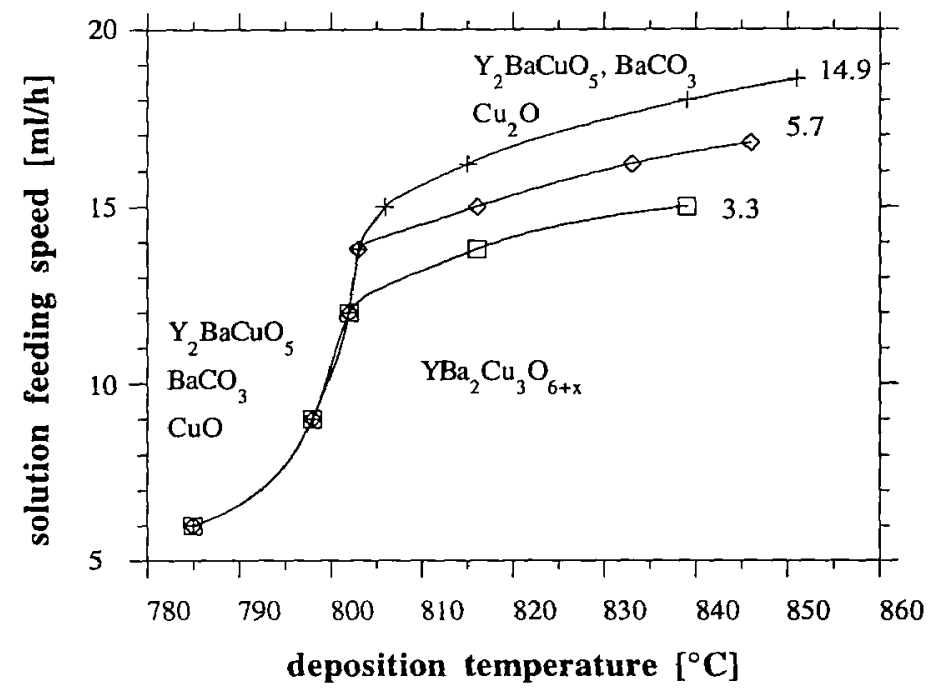

Figure 1: Stability of $\mathrm{YBa}_{2} \mathrm{Cu}_{3} \mathrm{O}_{6+x}$ as function of the solution feeding speed and deposition temperature for different $\mathrm{O}_{2} / \mathrm{Ar}$ ratios $(7.9,4.1,2.6)$. The superconducting phase is stable in the lower right corner of this figure and decomposes into $\mathrm{Y}_{2} \mathrm{BaCuO}_{5}, \mathrm{BaCO}_{3}$ and $\mathrm{CuO}$ (lower left corner) or into $\mathrm{Y}_{2} \mathrm{BaCuO}_{5}, \mathrm{BaCO}_{3}$ and $\mathrm{Cu}_{2} \mathrm{O}$ (top) over the stability line as determined by thermodynamic equilibrium calculations.

\subsubsection{Influence of the initial solution composition}

$\mathrm{YBa}_{2} \mathrm{Cu}_{3} \mathrm{O}_{6+\mathrm{x}}$ has no measurable solubility concerning the three metal atoms. Because it is very difficult to adjust and to maintain stable deposition conditions, secondary phases, even in extremely small amounts, are likely to be always present. To get an idea of the nature and the theoretical amount of this secondary phases, the deposited compounds as a function of the initial gas phase composition and the oxygen partial pressure have been calculated and are presented as pseudo-ternary diagrams (figure 2). The deposition temperature $\left(830^{\circ} \mathrm{C}\right)$, overall precursor concentration $(0.02 \mathrm{~mole} / \mathrm{l})$ and feeding speed $(10 \mathrm{ml} / \mathrm{h})$ have been kept constant. The point in the middle of the ternary diagrams corresponds to the composition, where the superconducting phase is deposited without secondary phases. Two iso-yield lines for 90 mole $\%$ and $80 \mathrm{~mol} \%$ of $\mathrm{YBa}_{2} \mathrm{Cu}_{3} \mathrm{O}_{6+\mathrm{x}}$ have also been included.

With decreasing oxygen partial pressure, the equilibrium phases are changing: for $\mathrm{O}_{2} / \mathrm{Ar}$ ratios greater than 4.2, $\mathrm{YBa}_{2} \mathrm{Cu}_{3} \mathrm{O}_{6+x}$ is in equilibrium with $\mathrm{Y}_{2} \mathrm{BaCuO}_{5}, \mathrm{BaCO}_{3}, \mathrm{BaCuO}_{2}$ and $\mathrm{CuO}$. This isoyields curve is particularly big towards $\mathrm{Y}_{2} \mathrm{BaCuO}_{5}$ and $\mathrm{BaCO}_{3}$, but this latter insulating compound is unfortunately known to precipitate at the grain boundaries of the superconductor, which is detrimental to the electrical properties. For lower oxygen partial pressures, $\mathrm{CuO}$ transforms into $\mathrm{Cu}_{2} \mathrm{O}$ and the iso-yield line opens towards the $\mathrm{Y}_{2} \mathrm{BaCuO}_{5}, \mathrm{Cu}_{2} \mathrm{O}, \mathrm{YBa}_{2} \mathrm{Cu}_{3} \mathrm{O}_{6+\mathrm{x}}$ three phase mixture. For $\mathrm{O}_{2} / \mathrm{Ar}$ ratios less than 2.1, $\mathrm{BaCuO}_{2}$ decomposes into $\mathrm{BaCO}_{3}$ and $\mathrm{Cu}_{2} \mathrm{O}$ and for an initial gas composition poor in $\mathrm{Y}(\mathrm{tmhd})_{3}$, the composition field for high yield of the superconducting phase becomes very narrow.

As a conclusion, if secondary phases are not to avoid, one should adjust the initial gas phase composition to fall inside a copper rich region with an oxygen partial pressure near or lower the $\mathrm{CuO} / \mathrm{Cu}_{2} \mathrm{O}$ equilibrium.

\subsubsection{Influence of the overall precursor concentration}

Another interesting question is, whether it is better to work with high precursor concentration in the solution and a low feeding speed or with a low concentration and a high feeding speed.

The stability limit $\mathrm{YBa}_{2} \mathrm{Cu}_{3} \mathrm{O}_{6+x} \rightarrow \mathrm{Y}_{2} \mathrm{BaCuO}_{5}, \mathrm{Cu}_{2} \mathrm{O} / \mathrm{CuO}, \mathrm{BaCO}_{3}$ has been determined as a function of deposition temperature and precursor crincentration for two different feeding speeds (figure 3 ). The $\mathrm{O}_{2}$ /Ar ratio has been kept at a constant value of 5.7. If one compares two different points with equal 

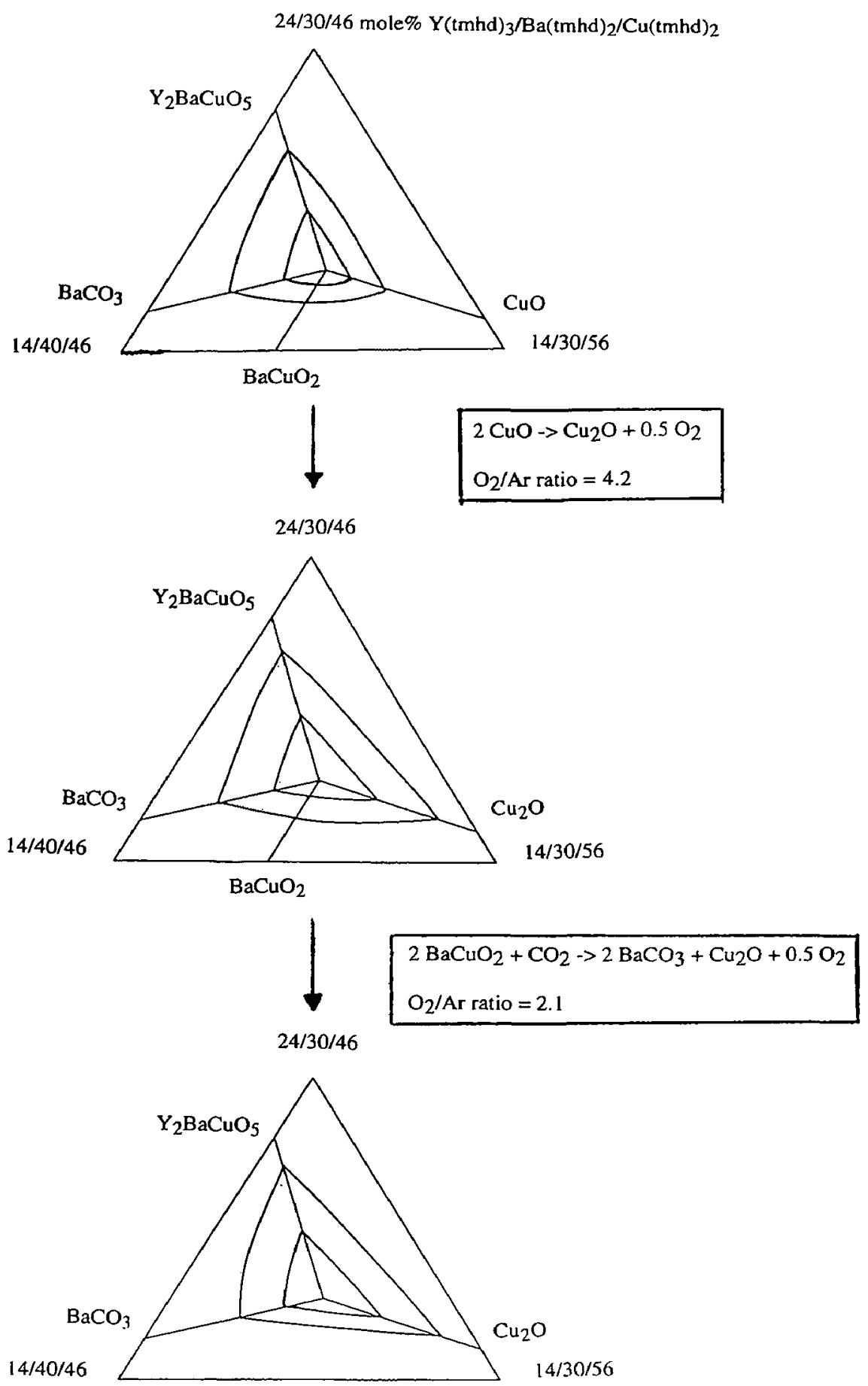

Figure 2: Compounds deposited as a function of initial gas composition depending on the (ha/Ar ration. The point in the

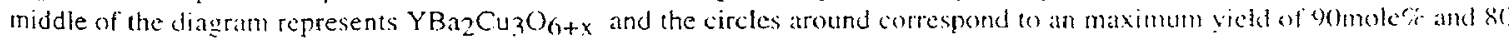
mole\%. 
deposition yield ( $14 \mathrm{ml} / \mathrm{h}-0.08 \mathrm{~mole} / 1$ and $16 \mathrm{ml} / \mathrm{h}-0.07 \mathrm{~mole} / \mathrm{l})$ a deposition temperature difference as high as $30^{\circ} \mathrm{C}$ for the stability line can be attained, which clearly indicates that high precursor concentrations and a moderate feeding speed should be favoured.

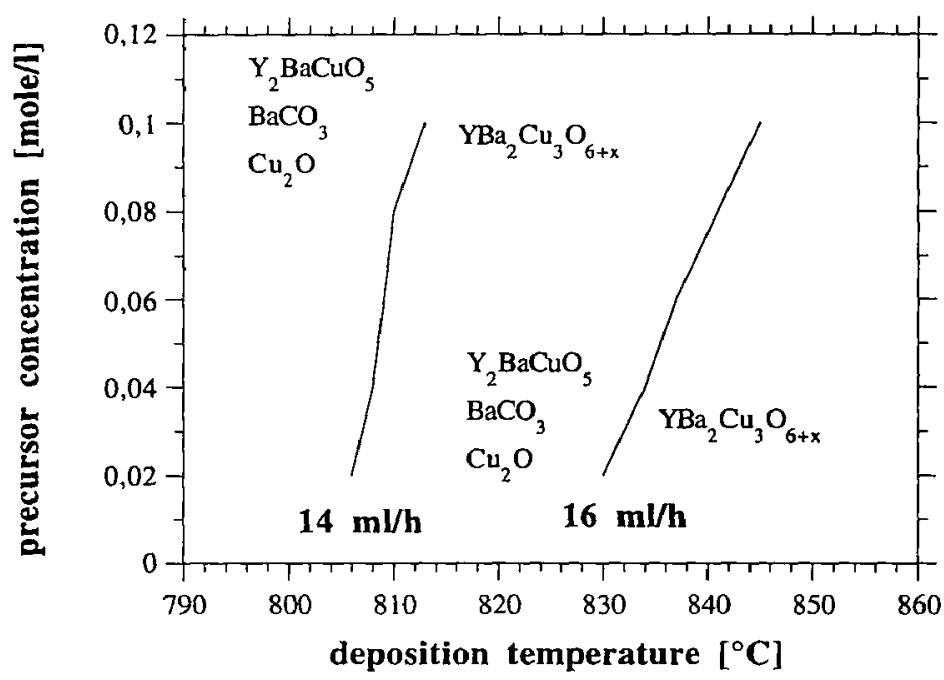

Figure 3: Stability of $\mathrm{YBa}_{2} \mathrm{Cu}_{3} \mathrm{O}_{6}+\mathrm{x}$ as a function of deposition temperature and precursor concentration for two different feeding speeds.

\subsection{Discussion}

According to the thermodynamic process simulation, the limiting step in the $\mathrm{YBa}_{2} \mathrm{Cu}_{3} \mathrm{O}_{6+x}$ process is the $\mathrm{CO}_{2}$ partial pressure causing decomposition of the superconducting compound into $\mathrm{BaCO}_{3}$ and other binary and ternary oxides. The origin of this $\mathrm{CO}_{2}$ partial pressure is the transformation of the carbon atoms in the organic solvent. Optimum growth conditions are therefore a total deposition pressure close to the room temperature vapour pressure of the solvent and a precursor concentration as high as possible. The solution feeding speed can then be decreased (which decreases the $\mathrm{CO}_{2}$ partial pressure) maintaining the same growth rate.

\section{EXPERIMENTAL RESULTS}

In order to establish the validity of our approach, some deposition experiments have been carried out, using the results of the equilibrium calculations as starting point. A high growth rate, which is equivalent to a high feeding speed, is the most important parameter for future applications. Three samples with a different solution feeding speed and deposition temperature have been prepared. The detailed description of the growth conditions is reported in table 2.

$\begin{array}{lll}\text { total pressure } & 10 \text { Torr } \\ \begin{array}{ll}\text { Or/Ar ration } \\ \text { precursor concentration }\end{array} & 7.6 \\ & & 0.02 \text { mole } / 1 \\ \text { sample \#1 } & \mathrm{T}_{D}=830^{\circ} \mathrm{C} & \mathrm{v}_{\text {feed }}=15 \mathrm{ml} / \mathrm{h} \\ \text { sample \#2 } & \mathrm{T}_{D}=780^{\circ} \mathrm{C} & \mathrm{v}_{\text {feed }}=15 \mathrm{ml} / \mathrm{h} \\ \text { sample \#3 } & \mathrm{T}_{D}=830^{\circ} \mathrm{C} & \mathrm{v}_{\text {feed }}=20 \mathrm{ml} / \mathrm{h}\end{array}$

Table 2: Experimental deposition conditions 
The precursor ratio ( $\left.\mathrm{Y}(\mathrm{tmhd})_{3}: \mathrm{Ba}(\mathrm{tmhd})_{2}: \mathrm{Cu}(\mathrm{tmhd})_{2}=1: 2.6: 2.3\right)$ has been adjusted so that the resulting film composition is as close as possible to $1: 2: 3$.

X-ray diffraction of the three samples show a strong texture with the c-axis of the film perpendicular to the substrate surface. Determination of the $c$ lattice parameter from the high angle 00l diffraction peaks of the layer, reveals a significant difference between the three samples: sample \#1 has a c value of $11.70 \AA$ which corresponds to a fully oxidised superconducting sample. The $c$ lattice parameter for the other two samples are distinctively smaller $(c=11.58 \AA$ for $\# 2$ and $c=11.64 \AA$ for \#3). Karen and Kjekshus [11] reported a certain solubility of $\mathrm{CO}_{2}$ in the structure of $\mathrm{YBa}_{2} \mathrm{Cu}_{3} \mathrm{O}_{6+x}$ resulting in a decreased $c$ lattice parameter with complete loss of the superconducting properties.

Resistivity and a.c. susceptibility measurements show good superconducting properties for sample $\# 1\left(\mathrm{~T}_{\mathrm{c}}=85 \mathrm{~K}\right.$ on $\mathrm{MgO}, 90 \mathrm{~K}$ on $\left.\mathrm{SrTiO}_{3}, \mathrm{j}_{\mathrm{c}}(77 \mathrm{~K})>10^{6} \mathrm{~A} / \mathrm{cm}^{2}\right)$. The two other samples are extremely resistive $(\mathrm{R}(300 \mathrm{~K})>100 \mathrm{~m} \Omega \mathrm{cm})$ without any superconducting transition, which supports the assumption of carbon contamination.

$\mathrm{CO}_{2}$ solubility and oxycarbonates have not been included in the equilibrium calculations because of missing thermodynamic data. However, the stability range of these compounds seems to be very narrow and their Gibbs free energy of formation should therefore not be considerably different from the three phase mixtures including $\mathrm{BaCO}_{3}$. So despite the fact, that these phases were not considered in the simulation, the determined stability limit should be rather correct, which is apparently the case.

A second set of samples has been prepared varying the metal composition and letting all other parameters identical to those of sample \#1. The critical transition temperatures for these samples (as determined by a.c. susceptibility) is plotted as a function of composition and is shown in figure 4 . In agreement with the predictions of the thermodynamic calculations, the highest $T_{C}$ values have been attained for copper rich composition. In the Ba-rich area of the pseudo-ternary diagram, the critical temperature decreases rapidly. X-ray diffraction analysis shows a secondary, highly textured phase, which can be either $\mathrm{BaCuO}_{2}$ or an Ba-rich oxycarbonate compound. The predicted $\mathrm{BaCO}_{3}$ is very often amorphous and preferentially located at grain boundaries, which makes it difficult to detect.

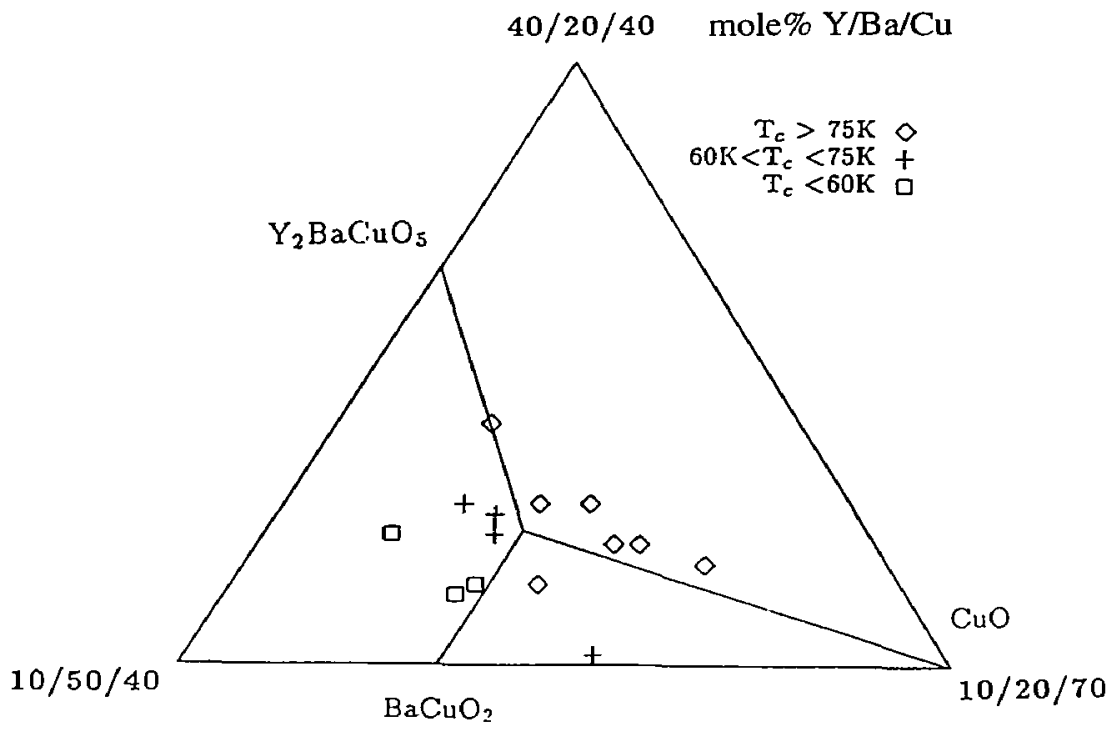

Figure 4: Critical superconducting transition temperatures as a function of composition 


\section{CONCLUSION}

Thermodynamic equilibrium calculations present generally a useful tool for optimising any elaboration process, if reliable Gibbs energy data for all compounds in the chemical system under investigation are available. The most important process parameters can be identified and a set of optimum conditions defined, which saves time and money. This approach has been applied to a novel aerosol CVD method for $\mathrm{YBa}_{2} \mathrm{Cu}_{3} \mathrm{O}_{6+\mathrm{x}}$ deposition. The limiting condition and most important parameter in this case is the $\mathrm{CO}_{2}$ partial pressure resulting in $\mathrm{BaCO}_{3}$ formation. This $\mathrm{CO}_{2}$ partial pressure is directly linked to the carbon content of the solvent. To achieve higher growth rates, new solvents have to be tested with lower room temperature vapour pressures, to decrease the total pressure in the reaction chamber, and - if possible - with a lower carbon content per volume.

\section{ACKNOWLEDGEMENT}

This work was founded by the Commission of the European Communities under BREU0203C and BRE2. CT94-742. One of the authors (A. Pisch) deeply acknowledges founding of his PhD thesis within the same framework.

\section{References}

[1] F. Schmaderer and G. Wahl, J. de Physique, Coll C5, 50 (1989), 119

[2] R. Hiskes, S. A. DiCarolis, J. L. Young, S. S. Laderman, R. D. Jacowitz and R. C. Taber Appl. Phys. Letters, 59(5) (1991), 606

[3] F. Weiss, K. Fröhlich, R. Haase, M. Labeau, D. Selbmann, J.P. Sénateur and O. Thomas J. de Physique IV C3,3 (1993), 321

[4] F. Weiss, K. Fröhlich, R. Haase, M. Labeau, D. Selbmann, J.P. Sénateur and O. Thomas EUCAS '93, Ed. H.C. Freyhardt, ISBN 3-88355-197-X DGM IG (1993), 403

[5] K. Fröhlich, F. Weiss, D. Boursier and J.P. Sénateur, Physica C, 235-240 (1993), 659

[6] A. Harsta and J. O. Carlsson, J. Cryst. Growth, 110 (1991), 631

[7] C. Vahlas and T. Besmann, J. Amer. Ceram. Soc., 75 (1992), 2679

[8] A. Pisch, $\mathrm{PhD}$ thesis, Institut National Polytechnique de Grenoble (1994)

[9] A. Pisch, F. Weiss and C. Bernard, Physica C, 235-240 (1993), 309

[10] J. N. Barbier and C. Bernard, presented atCALPHAD XV, Fulmer Grange, U.K. (1986)

[11] P. Karen and A. Kjekshus, J. of Solid State Chem., 94 (1991), 298 